\title{
Thermal properties and laser processing of hot-pressed materials from Ti-Al-C system
}

\author{
Paweł Rutkowski ${ }^{1}$ (D) Jan Huebner ${ }^{1} \cdot$ Dariusz Kata $^{1} \cdot$ Leszek Chlubny $^{1} \cdot$ Jerzy Lis $^{1} \cdot$ Katarzyna Witulska $^{1}$
}

Received: 16 July 2018/Accepted: 15 February 2019/Published online: 2 March 2019

(C) The Author(s) 2019

\begin{abstract}
The work concerns the characterization of polycrystalline materials composed in $\mathrm{Ti}-\mathrm{Al}-\mathrm{C}$ system such as $\mathrm{Ti}_{2} \mathrm{AlC}$ and $\mathrm{Ti}_{3} \mathrm{AlC}_{2}$. The starting powders were synthesized from metal powder in nitrogen overpressure with the use of SHS method. Such obtained powders were chemically described and hot-pressed at temperatures $1100{ }^{\circ} \mathrm{C}$ and $1300{ }^{\circ} \mathrm{C}$. The densification measurements were taken on obtained sintered bodies. The chemical composition analysis and microstructural observation of hot-pressed materials were made. The obtained MAX phase Young's modulus was examined in the temperature range $25-600{ }^{\circ} \mathrm{C}$ by resonance method. The thermal properties of the thermogravimetric analysis were made in air flow to determine the oxygen resistance. The MAX phase polycrystals were taken under laser flash analysis, which allowed to measure directly thermal diffusivity and specific heat and to calculate indirectly thermal conductivity up to the temperature of $700{ }^{\circ} \mathrm{C}$. Additionally, the polycrystalline material was laser treated in continuous work mode. The hotpressed MAX nanolaminates were laser ablation and laser welding processed, which is new in the literature. The laser beam-treated material places were microstructurally investigated by scanning electron microscopy and chemically by energy-dispersive X-ray spectroscopy. The result of laser processing was discussed regarding material preparation route and its thermal properties.
\end{abstract}

Keywords $\mathrm{Ti}_{3} \mathrm{AlC}_{2} \cdot \mathrm{Ti}_{2} \mathrm{AlC} \cdot \mathrm{MAX}$ phases $\cdot$ Thermal properties $\cdot$ Laser cutting $\cdot$ Laser welding

\section{Introduction}

MAX phases are thermodynamically stable nanolaminates, which have a $M_{n+1} A X_{n}$ stoichiometry, where $M$ stays for an early transition metal, $\mathrm{A}$ is an element of $\mathrm{A}$ groups (mostly IIIA or IVA), and $\mathrm{X}$ is carbon and/or nitrogen. This kind of structures is hexagonal, layered and has two types of bonds: metallic and covalent [1]. Such a structure is responsible for specific combination of material properties such as high stiffness, moderately low coefficient of thermal expansion and excellent thermal and chemical resistance with low hardness, good compressive strength, high fracture toughness, ductile behavior, good electrical and thermal conductivity which are characteristic for metals

Paweł Rutkowski

pawel.rutkowski@agh.edu.pl

1 Faculty of Materials Science and Ceramics, AGH University of Science and Technology in Krakow, al. A. Mickiewicza 30, 30-059 Krakow, Poland
[2-7]. The comprehensive information about properties, synthesis and applications of MAX phase materials in Ti$\mathrm{Al}-\mathrm{C}$ system can be found in complex and comprehensive review by Wang and Zhou [8] and latest work by Barsoum [9, 10] and Radovic [5].

The synthesis product will depend on reactant type, grain size, used synthesis technique and reactant mixture packing and thermal properties. In the literature data, the MAX phases are mostly obtained by combustion synthesis [11], mechanochemical synthesis [12], microwave-assisted synthesis [13] and polycrystalline materials by hot pressing $[14,15]$, spark plasma sintering [16, 17], hot isostatic pressing $[15,18]$ and slip casting assisted by pressure method [19].

Among many of Nowotny phases [20], the present work is focused on $\mathrm{Ti}_{2} \mathrm{AlC}$ and $\mathrm{Ti}_{3} \mathrm{AlC}_{2}$ materials. Based on literature data concerning thermal properties of these phases, the goal of the present work was to investigate elastic properties, thermal diffusivity and conductivity versus temperature. These properties values of the obtained 
materials were analyzed regarding different precursors used for the synthesis and density and phase composition of hot-pressed polycrystals. The second task of this work was to make laser attempts of the nanolaminate materials. Two types of laser process were taken for consideration: ablation and welding. Because of good thermal shock resistance of quasi-plastic materials [21] and their selfhealing properties [22], the hot-pressed sample was laser beam processed in severe conditions of continuous work mode.

\section{Preparation route and testing methods}

The reactants' mixtures used to obtain $\mathrm{Ti}_{2} \mathrm{AlC}$ and $\mathrm{Ti}_{3} \mathrm{AlC}_{2}$ MAX phases were prepared by the following powders: 99.7\% purity 149 micron titanium metal powder Ti-109 of Atlantic Equipment Engineers and 99.8\% purity 6.4 micron aluminum metal powder of Benda Lutz, Merck, graphite.

The MAX phases were synthesized by self-propagating high-temperature synthesis (SHS) in 1.5 atm argon overpressure. The reaction equation and the XRD/Rietveld phase composition of synthesis product are collected in Table 1 . The bold values of reagents in the reactions listed in Table 1 concern partial evaporation.

The products were initially ground in roll crusher and then milled with the use of rotary-vibratory mill in isopropanol environment for $4 \mathrm{~h}$. The "widia" (WC-Co) balls were used as milling media. Prepared powders were hotpressed (HP of Thermal Technology) in graphite molds. During the HP process, a pressure of $25 \mathrm{MPa}$ and argon flow were applied. The hot-pressing temperature was as follows: $1100{ }^{\circ} \mathrm{C}$ for $\mathrm{Ti}_{2} \mathrm{AlC}$ and $1300{ }^{\circ} \mathrm{C}$ for $\mathrm{Ti}_{3} \mathrm{AlC}_{2}$. The heating rate was $10^{\circ} \mathrm{Cmin}^{-1}$, and the samples were kept for $30 \mathrm{~min}$ at the maximum temperature.

The apparent density measurements of sintered composites were taken by means of a hydrostatic method, and then, the relative density was calculated. The qualitative and quantitative phase composition of polycrystalline materials was investigated by XRD (PANalytical X-ray
Diffractor (XRD) and X'pert HighScore software) and Rietveld methods. The microstructure of the material fractures was observed by Nova Nano SEM 200 scanning electron microscopy of FEI Europe Company.

The elastic properties measurements at elevated temperatures were taken by impulse excitation technique based on the analysis of the vibration of a test sample after it was "impulse excited" and resonance appeared. The test was made on plate samples by RFDA-1600HT of IMCE Company. The examined materials were heated up to $600{ }^{\circ} \mathrm{C}$ in air flow.

The thermal stability of chosen representative sample was measured in air flow by means of thermogravimetric TG measurements using NETZSCH STA 449 F3 Jupiter ${ }^{\circledR}$. This measurement was taken in order to explain the limitation of Young's modulus versus temperature measurements.

Thermal diffusivity measurements were taken by NETZSCH LFA 427 apparatus. This parameter was determined using the laser pulse method (LFA) for the reference and tested MAX material at temperatures ranging from 25 to $700{ }^{\circ} \mathrm{C}$ in argon flow, using the "Cape-Lehmann + pulse correction" computational model. At each temperature, three measurements were taken for statistical purposes. Thermal expansion coefficient (for density changes versus temperature) and specific heat were required to calculate thermal conductivity. The specific heat was determined by comparative method. Pyroceram 9606 reference material, with the known coefficient of thermal expansion and specific heat, was used for MAX material-specific heat calculation. Examination of tested material density changes as a function of temperature in the range up to $900{ }^{\circ} \mathrm{C}$ was performed by determining the coefficient of thermal expansion using a NETZSCH DIL $402 \mathrm{C}$ dilatometer. The thermal conductivity was calculated from the following equation:

$\lambda(T)=a(T) \cdot c_{\mathrm{p}}(T) \cdot q(T)$

where $a(T)$ is thermal diffusivity $\left(\mathrm{mm}^{2} \mathrm{~s}^{-1}\right), c_{\mathrm{p}}(\mathrm{T})$ specific heat $\left(\mathrm{Jg}^{-1} \mathrm{~K}^{-1}\right), q(T)$ density of the material $\left(\mathrm{gcm}^{-3}\right)$.

Table 1 Phase composition of SHS reaction bed

\begin{tabular}{|c|c|c|c|}
\hline Material & Sample no. & Reaction & Phase composition of SHS reaction bed/mass $\%$ \\
\hline \multirow[t]{3}{*}{$\mathrm{Ti}_{2} \mathrm{AlC}$} & 1 & $2 \mathrm{Ti}+\mathrm{Al}+\mathrm{C} \rightarrow \mathrm{Ti}_{2} \mathrm{AlC}$ & $63.4 \% \mathrm{Ti}_{2} \mathrm{AlC}, 15.7 \% \mathrm{Ti}_{3} \mathrm{AlC}_{2}, 10.9 \% \mathrm{TiC}$ \\
\hline & 2 & 1.2 $\mathrm{TiAl}+\mathrm{Ti}+\mathrm{C} \rightarrow \mathrm{Ti}_{2} \mathrm{AlC}$ & $95.4 \% \mathrm{Ti}_{2} \mathrm{AlC}, 4.6 \% \mathrm{TiAl}_{2}$ \\
\hline & 3 & $1.05 \mathrm{TiAl}+\mathrm{Ti}+\mathrm{C} \rightarrow \mathrm{Ti}_{2} \mathrm{AlC}$ & $87.5 \% \mathrm{Ti}_{2} \mathrm{AlC}, 10.8 \% \mathrm{Ti}_{3} \mathrm{AlC}_{2}, 1.6 \% \mathrm{TiC}$ \\
\hline \multirow[t]{3}{*}{$\mathrm{Ti}_{3} \mathrm{AlC}_{2}$} & 4 & 1.1TiAl $+2 \mathrm{Ti}+2 \mathrm{C} \rightarrow \mathrm{Ti}_{3} \mathrm{AlC}_{2}$ & $73.8 \% \mathrm{Ti}_{3} \mathrm{AlC}_{2}, 11.3 \% \mathrm{Ti}_{2} \mathrm{AlC}, 14.8 \% \mathrm{TiC}$ \\
\hline & 5 & $\mathrm{TiAl}+2 \mathrm{Ti}+2 \mathrm{C} \rightarrow \mathrm{Ti}_{3} \mathrm{AlC}_{2}$ & $71.4 \% \mathrm{Ti}_{3} \mathrm{AlC}_{2}, 7.9 \% \mathrm{Ti}_{2} \mathrm{AlC}, 20.7 \% \mathrm{TiC}$ \\
\hline & 6 & $1.2 \mathrm{Ti}_{3} \mathrm{Al}+2 \mathrm{C} \rightarrow \mathrm{Ti}_{3} \mathrm{AlC}_{2}$ & $10.8 \% \mathrm{Ti}_{3} \mathrm{AlC}_{2}, 64.0 \% \mathrm{Ti}_{2} \mathrm{AlC}, 24.2 \% \mathrm{TiC}, 1 \% \mathrm{C}$ \\
\hline
\end{tabular}


The hot-pressed polycrystalline materials were subjected to the cutting and welding test using the JK200FL ytterbium-doped fiber laser beam. The processing way of laser welding and cutting is described in Fig. 1. The welding process was made in continuous laser work (CW) mode. The following parameters of laser treatment were used: $1064 \mathrm{~nm}$ wave length, $100 \mathrm{~W}$ laser power, $1000 \mu \mathrm{m}$ beam spot and very low $0.5 \mathrm{mms}^{-1}$ scanning speed. In case of subtractive laser processing there were used four values of laser power: 60, 80, 100 and $120 \mathrm{~W}$. The laser beam was focused on the surface in order to obtain 40-micron spot. In comparison with the welding process, the cut in the material was made with $10 \mathrm{mms}^{-1}$ laser beam travel.

The observation of the cut and weld surface and cross section was performed by Leica optical microscope and Nova Nano SEM 200 scanning electron microscope. Additionally, the chemical composition changes in the weld and cut material were investigated by energy-dispersive X-ray spectroscopy (EDS of EDAX) method. The influence of laser power on the cutting process was investigated by checking of cavity's width and length dimensions by optical microscope. All kinds of the afterlaser treatment material area examinations are presented in Fig. 2.

\section{Phase analysis, microstructure and densification}

The qualitative and quantitative phase composition analysis of hot-pressed MAX polycrystals is collected in Table 2 for different sintering conditions and material phases. It contains also density data of obtained samples. All of the $\mathrm{Ti}_{2} \mathrm{AlC}$ polycrystalline materials show low density between 66 and $76 \%$, but high material purity in case of samples 2 and 3 . In case of $\mathrm{Ti}_{3} \mathrm{AlC}_{2}$ material, the relative density was

\section{CUTTING}

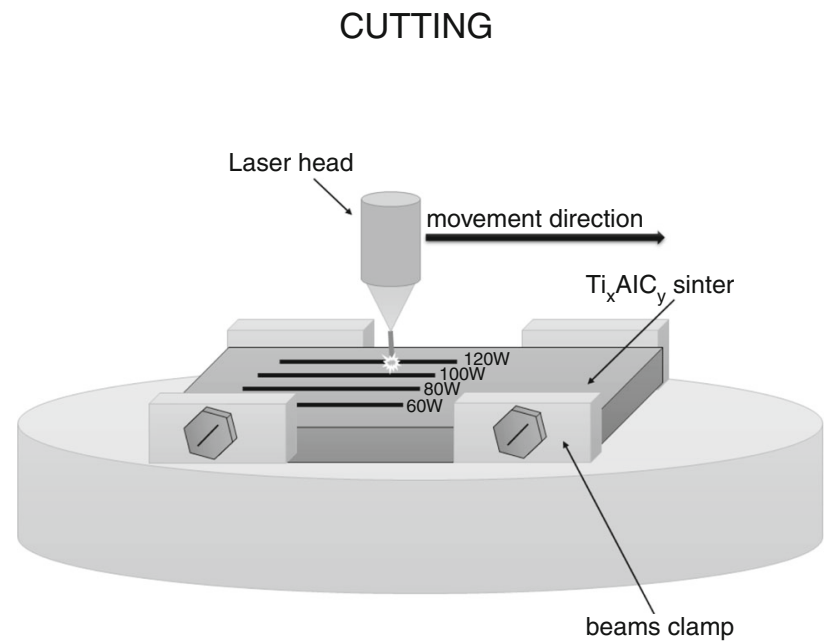

above $95 \%$ and high MAX phase purity was obtained for samples 4 and 5 .

The manufactured $\mathrm{Ti}_{2} \mathrm{Al}$ and $\mathrm{Ti}_{3} \mathrm{AlC}_{2}$ nanolaminate sinters were taken under microstructural observations. The images of material fractures investigated by scanning electron microscopy method are shown in Fig. 3-8.

The microstructural observations of samples confirm the existence of laminate structures of MAX phases. Samples 4 and 5 show almost pure MAX structure mostly with $\mathrm{Ti}_{3}$ $\mathrm{AlC}_{2}$ phase (Fig. 4, 6, 8). The microstructure images of $\mathrm{Ti}_{3} \mathrm{AlC}_{2}$ samples show characteristic layered structure typical for MAX phases. The material fracture confirms high densification of MAX phases in case of $\mathrm{Ti}_{3} \mathrm{AlC}_{2}$ samples-which is difficult to obtain with high heating rate of $10^{\circ} \mathrm{Cmin}^{-1}$. For $\mathrm{Ti}_{2} \mathrm{AlC}$ the microstructure is finer and much more porous, which is confirmed by relative density not exceeding $76 \%$. In these samples, there are some visible small cubic grains of titanium carbide phase (Fig. 3, 5, 7). The $\mathrm{Ti}_{2} \mathrm{AlC}$ (Fig. 3, 5) has no tendency for directional sintering - there is isotropy of properties.

\section{Elastic properties versus Temperature}

Because of potential application at elevated temperature of $\mathrm{Ti}_{\mathrm{x}} \mathrm{AlC}_{\mathrm{y}}$-based materials, the elastic modulus was measured versus temperature by resonance method-Fig. 9. In case of $\mathrm{Ti}_{2} \mathrm{AlC}$-based materials, there is no visible change in Young's modulus values versus temperature. The values are between 50 and $125 \mathrm{GPa}$, what is much lower than in the literature [24]. It is caused mostly by high material porosity. They have open porosity between 23 and $34 \%$. For this samples phase composition does not influence elastic properties. In case of $\mathrm{Ti}_{3} \mathrm{AlC}_{2}$-based composites, the E modulus decreases slightly by about $10 \%$ in $25-600{ }^{\circ} \mathrm{C}$ temperature range. The elastic modulus of the $\mathrm{Ti}_{3} \mathrm{AlC}_{2}$

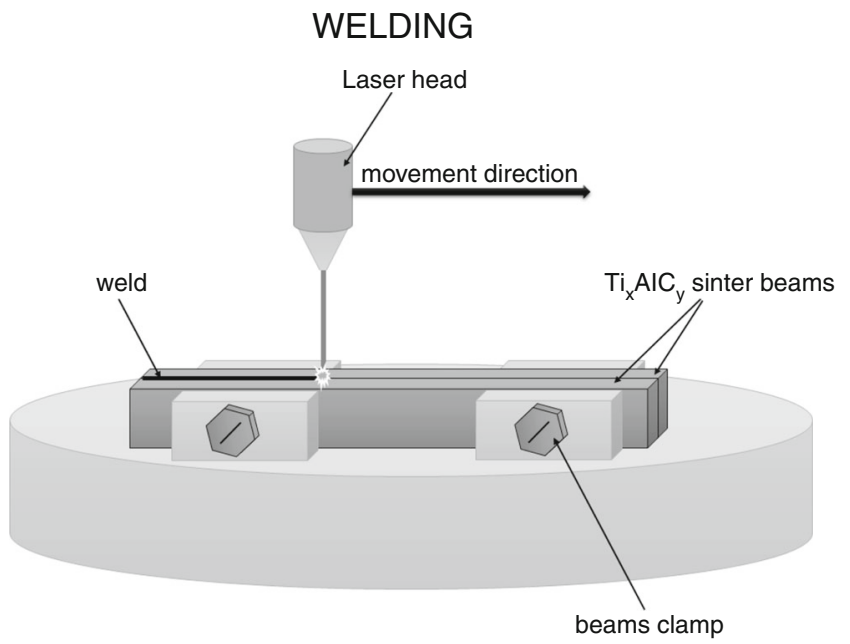

Fig. 1 Schematic drawing of MAX polycrystalline materials cutting and welding process 
Fig. 2 Schematic drawing of taken examinations of the lasertreated nanolaminates

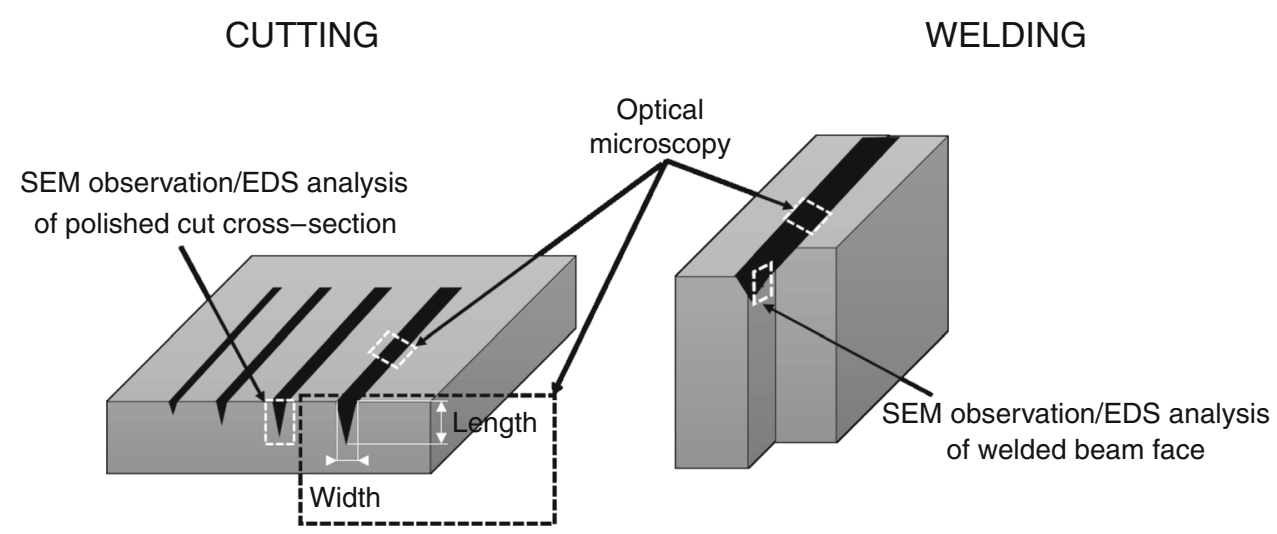

Table 2 Phase composition and densification of hot-pressed Ti-Al-C system materials [23]

\begin{tabular}{|c|c|c|c|c|c|}
\hline Material & Sample no. & Sintering conditions & Polycrystal phase composition/mass $\%$ & $\begin{array}{l}\text { Apparent } \\
\text { density/gcm } \\
-3\end{array}$ & $\begin{array}{l}\text { Relative } \\
\text { density } / \%\end{array}$ \\
\hline \multirow{3}{*}{$\mathrm{Ti}_{2} \mathrm{AlC}$} & 1 & \multirow[t]{3}{*}{ 1100, Ar, $30 \mathrm{~min}$} & $62.8 \% \mathrm{Ti}_{2} \mathrm{AlC}, 30.1 \% \mathrm{Ti}_{3} \mathrm{AlC}_{2}, 2.8 \% \mathrm{TiC}, 4.3 \% \mathrm{Al}_{2} \mathrm{O}_{3}$ & 3.14 & 76.4 \\
\hline & 2 & & $98.7 \% \mathrm{Ti}_{2} \mathrm{AlC}, 1.3 \% \mathrm{TiC}$ & 2.96 & 72.1 \\
\hline & 3 & & $88.3 \% \mathrm{Ti}_{2} \mathrm{AlC}, 10.2 \% \mathrm{Ti}_{3} \mathrm{AlC}_{2}, 1.5 \% \mathrm{TiC}$ & 2.79 & 65.9 \\
\hline \multirow[t]{3}{*}{$\mathrm{Ti}_{3} \mathrm{AlC}_{2}$} & 4 & \multirow[t]{3}{*}{ 1300, Ar, $30 \mathrm{~min}$} & $90.3 \% \mathrm{Ti}_{3} \mathrm{AlC}_{2}, 9.7 \% \mathrm{TiC}$ & 4.20 & 98.8 \\
\hline & 5 & & $86.8 \% \mathrm{Ti}_{3} \mathrm{AlC}_{2}, 13.2 \% \mathrm{TiC}$ & 4.21 & 99.1 \\
\hline & 6 & & $38.6 \% \mathrm{Ti}_{3} \mathrm{AlC}_{2}, 41.4 \% \mathrm{Ti}_{2} \mathrm{AlC}, 20.0 \% \mathrm{TiC}$ & 4.04 & 95.1 \\
\hline
\end{tabular}

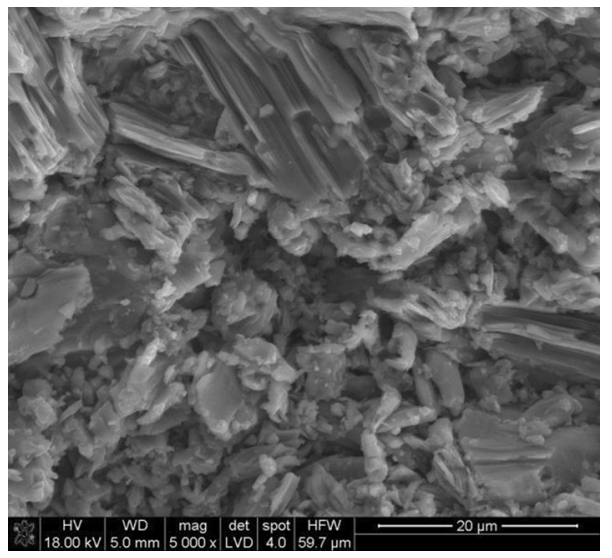

Fig. 3 Sintered $\mathrm{Ti}_{2} \mathrm{AlC}$ sample 1 nanolaminate

nanolaminate samples 4 and 5 (high density) is about 325 GPa which is similar to the values presented in the literature [25, 26]. Sample 6 has lower Young's modulus at about $275 \mathrm{GPa}$. This can be partially caused by multiphase material composition, where $41 \%$ of the material is occupied by $\mathrm{Ti}_{2} \mathrm{AlC}$ phase with lower $260 \mathrm{GPa}$ elastic modulus [7] and lower densification of $95 \%$. The decrease in Young's modulus in case of these nanolaminate materials is similar to the presented $\mathrm{Ti}_{2} \mathrm{AlC}$ by Kozak et al. [27]

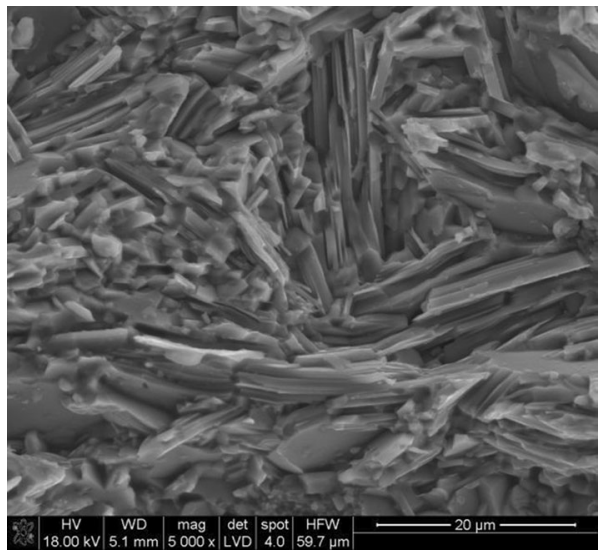

Fig. 4 Sintered $\mathrm{Ti}_{3} \mathrm{AlC}_{2}$ sample 3 nanolaminate [23]

The material oxidation occurs during measurements even in argon atmosphere. The thin oxide layers cause the lack of the signal at higher temperature above $600{ }^{\circ} \mathrm{C}$ (Fig. 9). This is compatible with the oxidation analysis data obtained from TG method measurements made in air flow. The oxidation starts at around $400{ }^{\circ} \mathrm{C}$, which is presented in Fig. 10. The oxidation resistance of the material was not studied in detail because there is a lot of such data in the literature concerning titanium aluminum carbide [28-32]. 


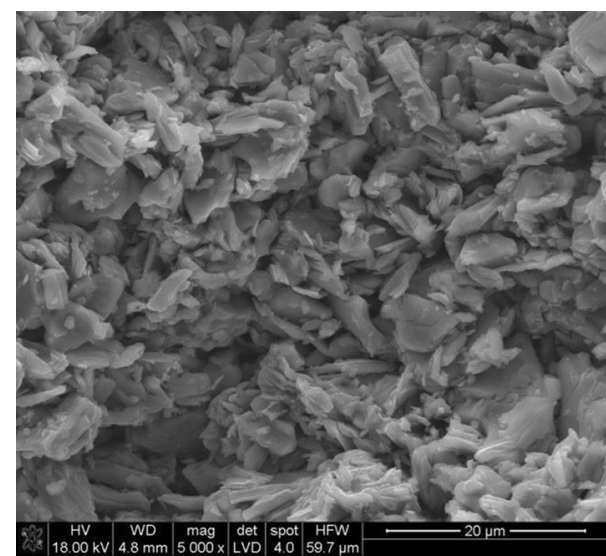

Fig. 5 Sintered $\mathrm{Ti}_{2} \mathrm{AlC}$ sample 2 nanolaminate

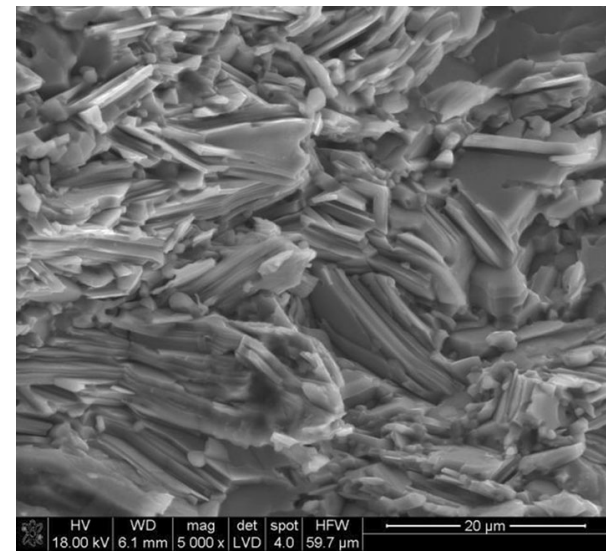

Fig. 6 Sintered $\mathrm{Ti}_{3} \mathrm{AlC}_{2}$ sample 5 nanolaminate

\section{Thermal properties}

In the case of $\mathrm{Ti}_{2} \mathrm{AlC}$, the thermal diffusivity rises with an increase in material density. The low values of thermal properties can be explained also by fine material microstructure, so higher concentration of flat defectsFigs. 3, 5, 7. This parameter decreases with an increase in temperature-Fig. 11. Thermal conductivity values are shown in Fig. 13. It is caused by phonon scattering processes which depend on material purity. That is why higher densified $\mathrm{Ti}_{2} \mathrm{AlC}$ sample 1 with purity of $63 \%$ has lower value heat transport than sample 2 with purity of almost $99 \%$ and relative density of $72 \%$.

In case of $\mathrm{Ti}_{3} \mathrm{AlC}_{2}$ the thermal diffusivity reaches 11 $\mathrm{mm}^{2} \mathrm{~s}^{-1}$ for sample 4 with highest MAX phase purity of $90 \%$ - Fig. 12. This sample has slightly lower densification by $1.3 \%$ than sample 5 with higher values of thermal diffusivity (Fig. 12). So in case of well hot-pressed $\mathrm{Ti}_{3} \mathrm{AlC}_{2}$ material, the slight difference in porosity values between samples is not as important as material purity. Therefore,

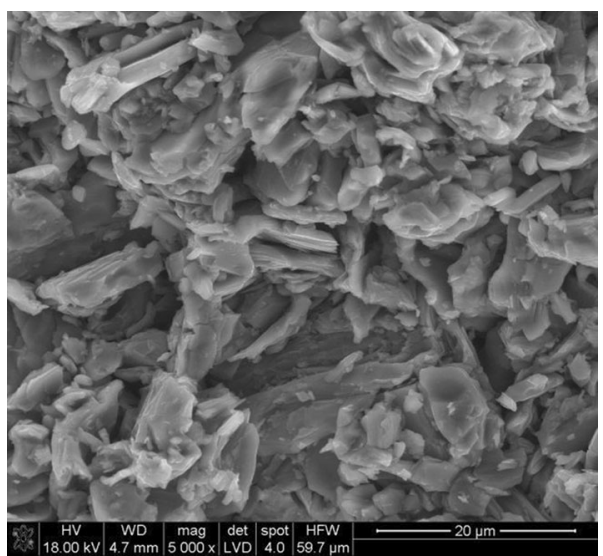

Fig. 7 Sintered $\mathrm{Ti}_{2} \mathrm{AlC}$ sample 3 nanolaminate

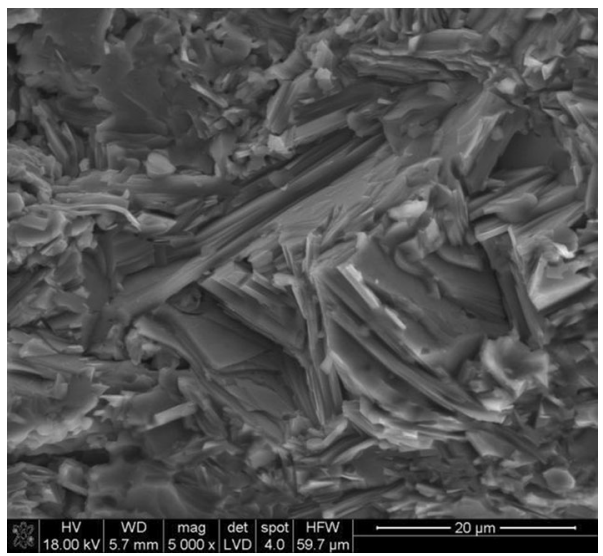

Fig. 8 Sintered $\mathrm{Ti}_{3} \mathrm{AlC}_{2}$ sample 6 nanolaminate

material purity influences the phonons scattering degree and the following thermal properties. Due to larger grain size and lower concentration of flat defects the thermal properties of this MAX material are also high and similar to the data reported in the literature [33]. Based on the measured thermal diffusivity and material specific, the thermal conductivity of $\mathrm{Ti}_{3} \mathrm{AlC}_{2}$ samples was calculated and is illustrated in Fig. 14.

\section{Laser cutting and welding process}

The areas/places of chosen $\mathrm{Ti}_{2} \mathrm{AlC}$ and $\mathrm{Ti}_{3} \mathrm{AlC}_{2}$ nanolaminates after laser cutting process were microscopy observed, and their dimensions were measured. The recorded data and observation of after-process cavity filling by the material are collected in Table 3 .

The data in Table 3 show that both of the dimensions of the interaction zone after laser processing were increased with a laser power rise. Comparing two different material 


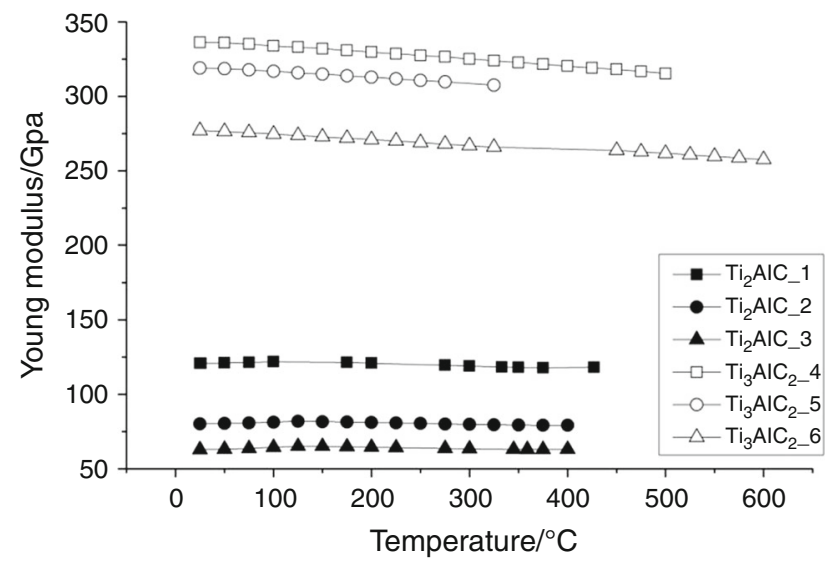

Fig. 9 Young's modulus changes versus temperature of $\mathrm{Ti}_{\mathrm{x}} \mathrm{AlC}_{\mathrm{y}}-$ sintered nanolaminates

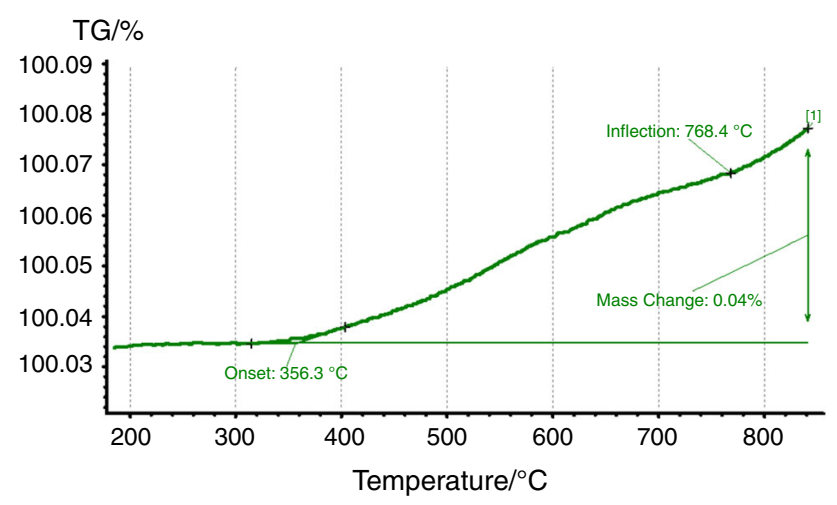

Fig. 10 Oxidation process of $\mathrm{Ti}_{3} \mathrm{AlC}_{2}$-sintered material

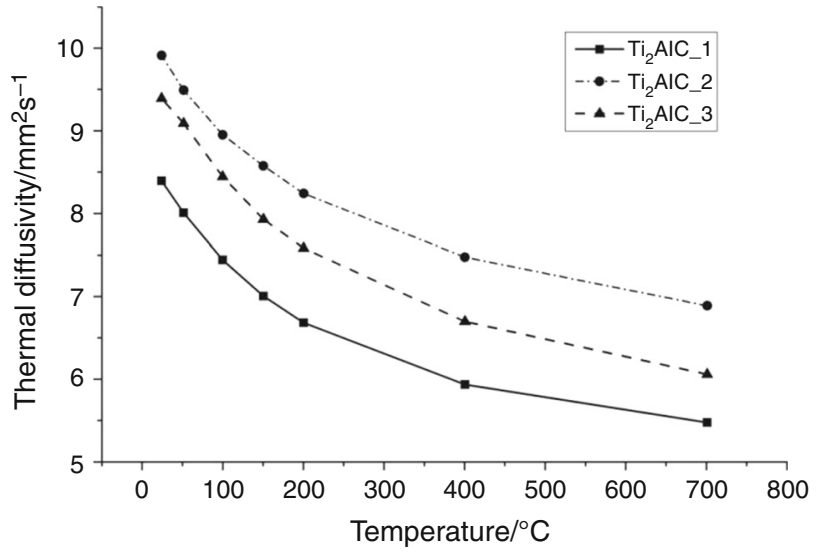

Fig. 11 Thermal diffusivity of sintered $\mathrm{Ti}_{2} \mathrm{AlC}$ nanolaminates

samples, it can be noticed that the width and depth dimension values of the cavity in case of $\mathrm{Ti}_{2} \mathrm{AlC}$ material are much higher than for $\mathrm{Ti}_{3} \mathrm{AlC}_{2}$. It is caused by the higher $\mathrm{Ti}_{2} \mathrm{AlC}$ porosity (Table 2 ) and following it lower thermal conductivity values (Fig. 11-12). Low thermal data resulted in temperature isolation in the interaction area and

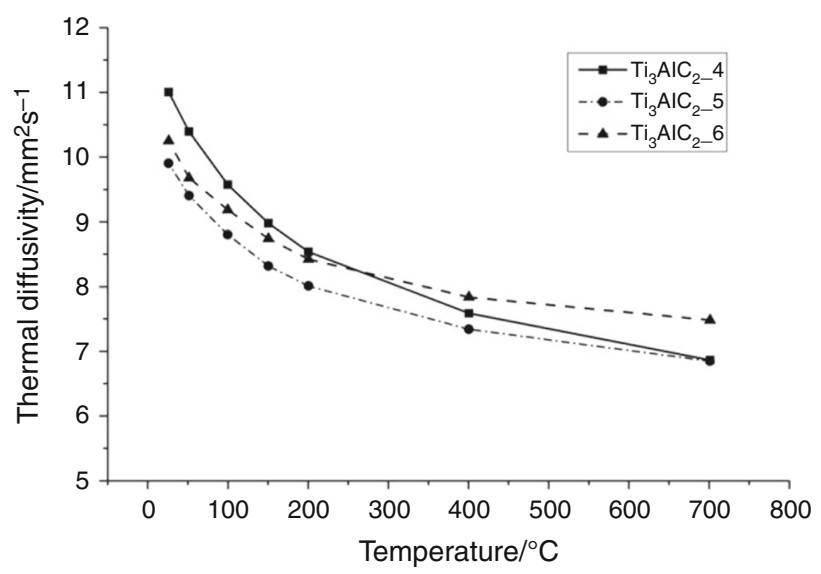

Fig. 12 Thermal diffusivity of sintered $\mathrm{Ti}_{3} \mathrm{AlC}_{2}$ nanolaminates

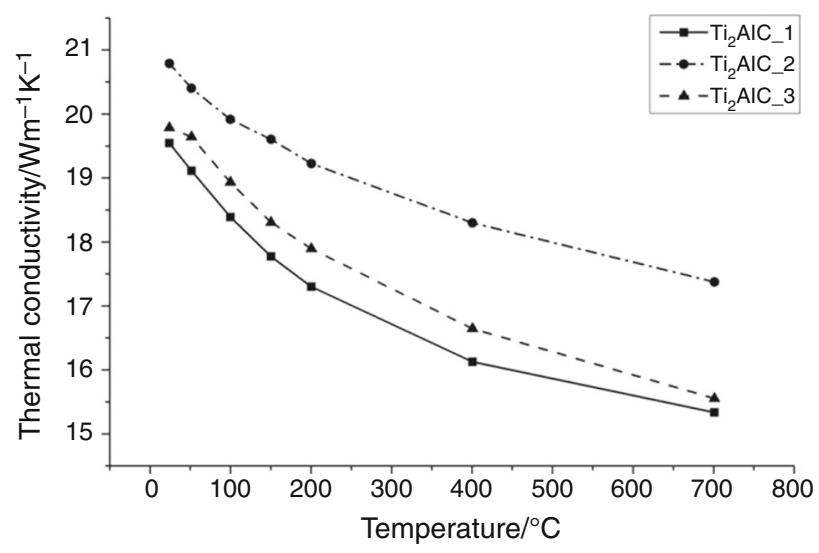

Fig. 13 Thermal conductivity of sintered $\mathrm{Ti}_{2} \mathrm{AlC}$ nanolaminates

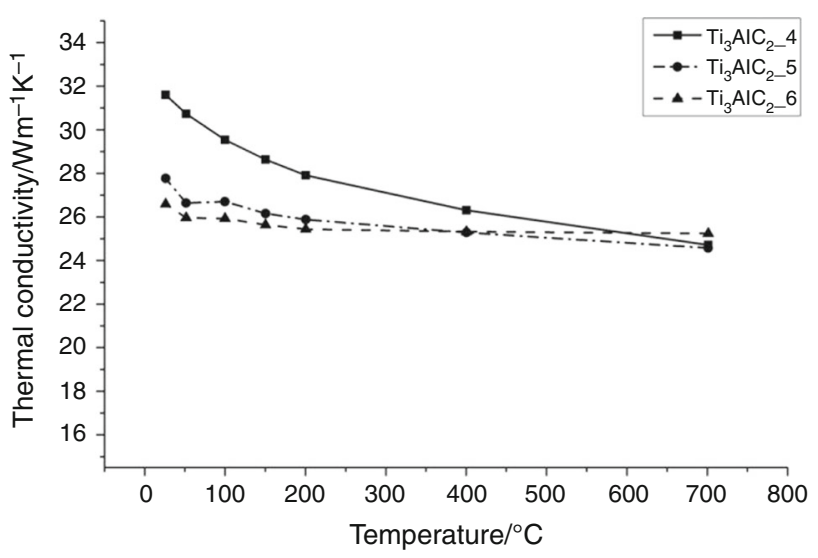

Fig. 14 Thermal conductivity of sintered $\mathrm{Ti}_{3} \mathrm{AlC}_{2}$ nanolaminates

higher laser process temperature. The increased process temperature caused deeper laser penetration and material evaporation from the cavity supported by argon gas flow from the laser head nozzle. Some of the melted materials 
probably recrystallized in the pours of laser-treated material area causing densification of material heat-affected zones-Fig. 15c, f. This situation gives the plausible laser application for MAX phases as material healing or densification process leading to modification of material, for example surface properties.

In case of $\mathrm{Ti}_{3} \mathrm{AlC}_{2}$ material with higher thermal conductivity (in comparison with $\mathrm{Ti}_{2} \mathrm{AlC}$ ), the scratch after laser processing was shallower and the after-cutting process cavity was filled with the material (Fig. 16) which was promising for material curing and welding process (Fig. 17).

The surface and cross-sectional observation of the material places modified by the laser beam during cutting process are illustrated on the assembly drawing in Fig. 15 in case of $\mathrm{Ti}_{2} \mathrm{AlC}$ and in Fig. 14 for $\mathrm{Ti}_{3} \mathrm{AlC}_{2}$ sample.

In case of $\mathrm{Ti}_{2} \mathrm{AlC}$ nanolaminate material the polished cross section showed that cut is irregular which was caused by the thermal stresses and microcracks generated as a result of laser beam work in aggressive continuous mode.
The cut is empty inside, so part of the material was evaporated, and the melted material parts were removed by the protective argon gas flowing from the laser head nozzle with overpressure of 2 bars or recrystallized in the material's pours during fast $10 \mathrm{mms}^{-1}$ process rate-Fig. $15 \mathrm{~b}$. The image in Fig. 15e confirmed that there is no material on cut surface (upper part of the cut) and some of the material was deposited in the area closed to the cut edges. The illustrations in Fig. 15c and $\mathrm{f}$ present dense 50 microns layer of nanolaminate material close to inner edges of the cut. In this area, the nanolaminate MAX structures are visible and the orientation of the structures (Fig. 15f) in perpendicular direction of the cutting can be a result of the anisotropy in heat flow during laser treatment. Figure $15 \mathrm{~d}$ illustrates the material under the cutting tip. The large and small nanolaminate grains are visible in this area as the result of the melting and decomposition process. The small cracks between grains in this area can be caused by the shock wave. For all of the cuts made by the laser beam in the range $60-120 \mathrm{~W}$ the cross-sectional surface
Table 3 Interaction area dimension versus laser power during cutting process

\begin{tabular}{lllrrrr}
\hline Material & Dimensions & \multicolumn{3}{l}{ Laser power/W } & & Cavity filling by material \\
\cline { 3 - 5 } & & 60 & \multicolumn{1}{c}{80} & 100 & 120 & \\
\hline Ti ${ }_{2} \mathrm{AlC}$ sample 2 & Width $/ \mu \mathrm{m}$ & 172 & 251 & 314 & 402 & No \\
& Depth $/ \mu \mathrm{m}$ & 865 & 1194 & 1245 & 1754 & \\
$\mathrm{Ti}_{3} \mathrm{AlC}_{2}$ sample 5 & Width $/ \mu \mathrm{m}$ & 123 & 189 & 230 & 255 & Yes \\
& Depth $/ \mu \mathrm{m}$ & 107 & 609 & 785 & 872 & \\
\hline
\end{tabular}
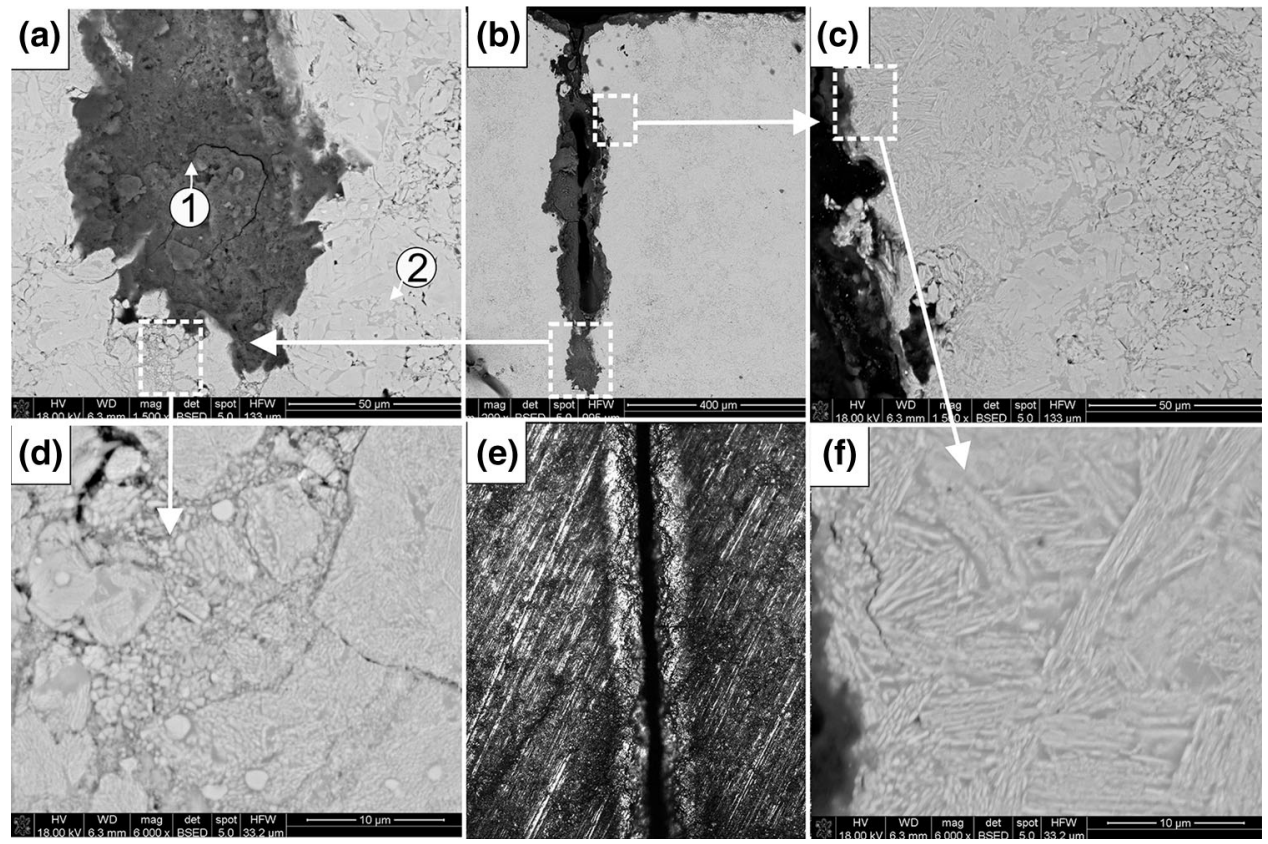

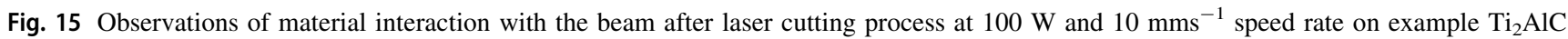
sample 2 


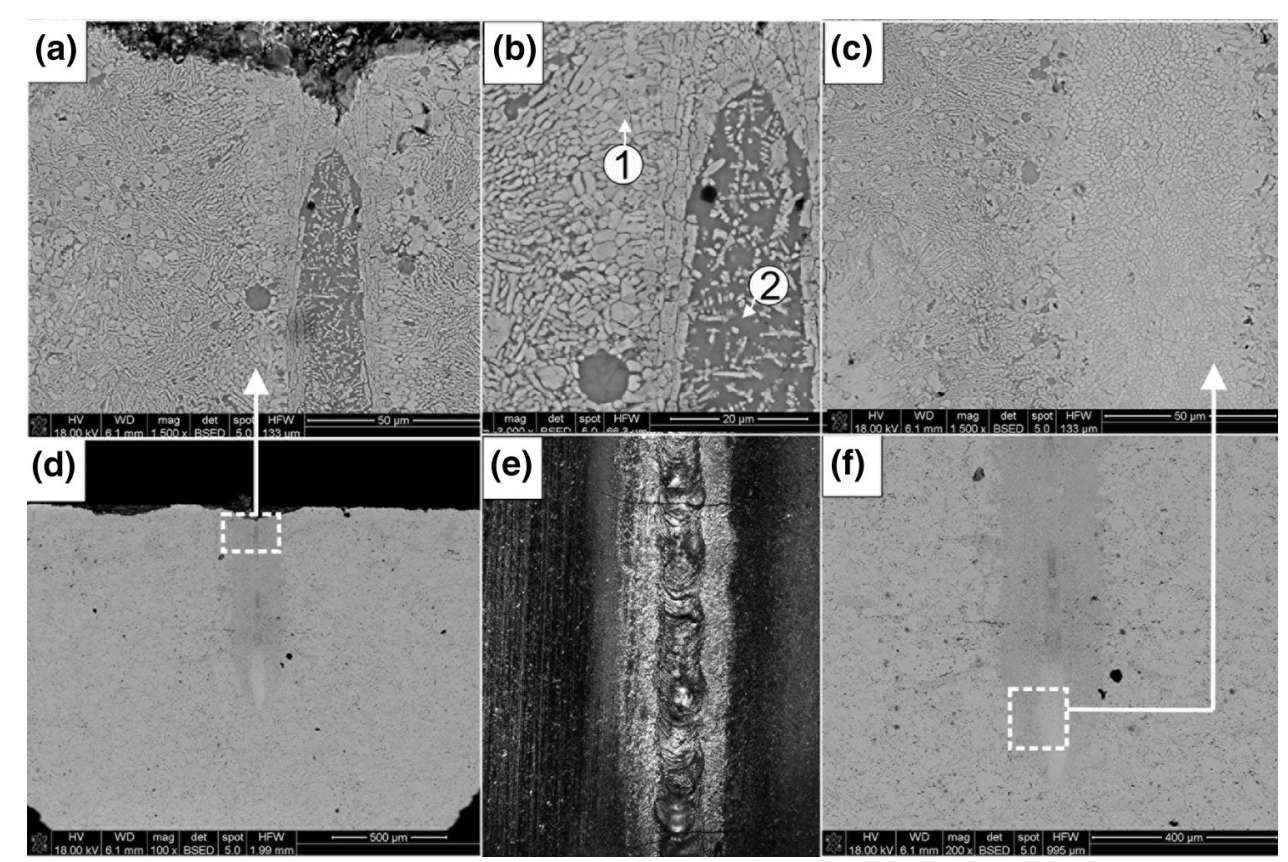

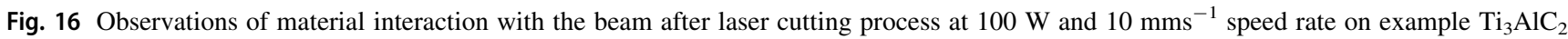
sample 5

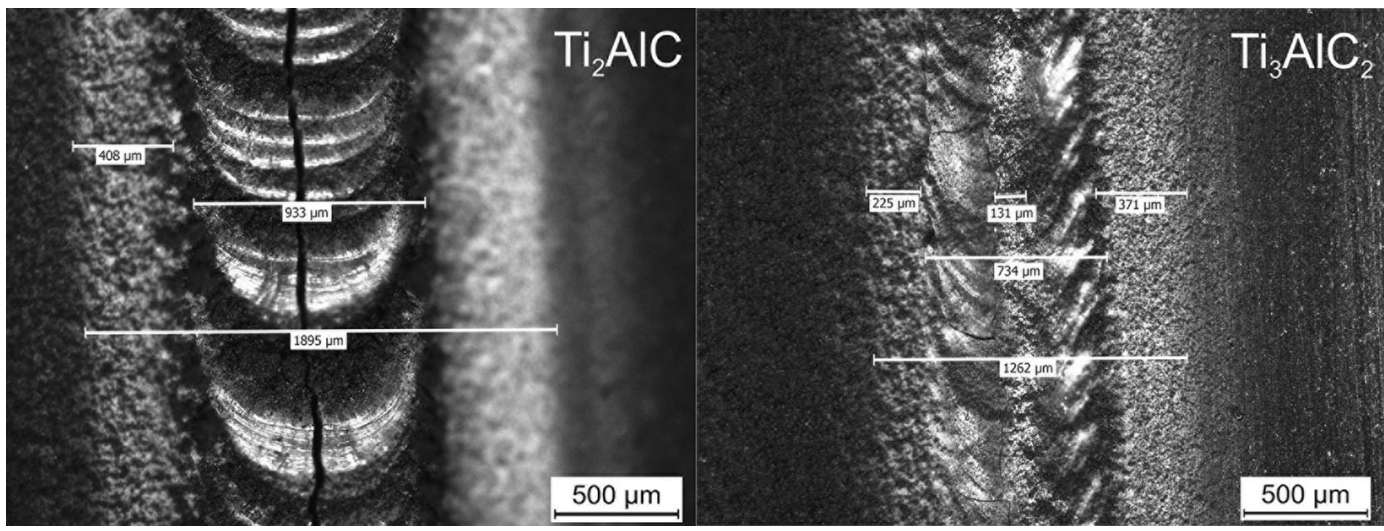

Fig. 17 Weld area of $\mathrm{Ti}_{3} \mathrm{AlC}_{2}$ and $\mathrm{Ti}_{2} \mathrm{AlC}$ MAX phase materials, at $\mathrm{CW}$ mode, $100 \mathrm{~W}$ and $0.5 \mathrm{mms}^{-1}$ laser conditions

microstructural observations are all similar. From element distribution analysis collected in Table 4 the dark phase in the tip of laser cut area (Fig. 13a) comes from the silica polishing agent. The second point of EDS analysis in Fig. 15a contains $\mathrm{Ti}, \mathrm{Al}$ and $\mathrm{C}$ elements which can indicate on MAX and TiC phase existence in this area.

The observations of the cut area for $\mathrm{Ti}_{3} \mathrm{AlC}_{2}$ nanolaminate polycrystalline material as a result of the laser beam interaction are presented in Fig. 16. From the side of the cut surface Fig. 16e shows the cut filled with the melted and recrystallized material, which visually is similar to the weld material. Only few cracks are visible as a result of fast surface cooling rate (fast laser beam movement). The entire cut cross section is shown in Fig. 16d and magnified one in Fig. 16f. Similar to the surface observations (made by optical microscope), the scanning electron microscopy examinations revealed fully dense-filled cut cavity with almost no microcracks. This cut was made also in argon flow under 2 bars overpressure coming from the laser head nozzle. That situation can be promising for laser welding process, which will be discussed in the further part of this work. The filling of the after-laser cut cavity by the recrystallized phase is also promising for material laser healing treatment. The general cross-sectional image shows also that the material filling of the cut is composed of different zones, which are presented in Fig. 16a-b. There is 
Table 4 Element distribution analysis (EDS) of material after laser cutting process

\begin{tabular}{lllllll}
\hline Material & Figure no. & Analysis point & \multicolumn{4}{l}{ Content of element/mass\% } \\
\cline { 4 - 6 } & & & $\mathrm{Ti}$ & $\mathrm{Al}$ & $\mathrm{C}$ & $\mathrm{O}$ \\
\hline Ti ${ }_{2} \mathrm{AlC}$ sample 2 & Figure 15 & 1 & \multicolumn{4}{l}{ Silica coming from polishing process } \\
& & 2 & 7.93 & 22.56 & 7.93 & 0 \\
$\mathrm{Ti}_{3} \mathrm{AlC}_{2}$ sample 5 & Figure 16 & 1 & 52.69 & 46.41 & 0.90 & 0 \\
& & 2 & 73.32 & 11.92 & 14.76 & 0 \\
\hline
\end{tabular}

$\mathrm{C}-1.40$ mass $\%$
$\mathrm{O}-40.61$ mass $\%$
$\mathrm{Al}-10.44$ mass $\%$
$\mathrm{Ti}-47.55$ mass $\%$

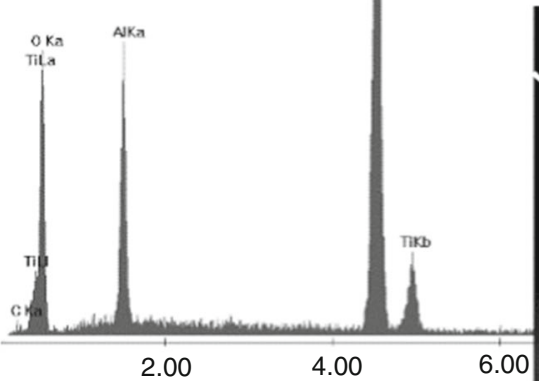

C -5.22 mass $\%$

$\mathrm{O}-6.50$ mass $\%$

$\mathrm{Al}-13.20$ mass $\%$

$\mathrm{Ti}-75.08$ mass $\%$

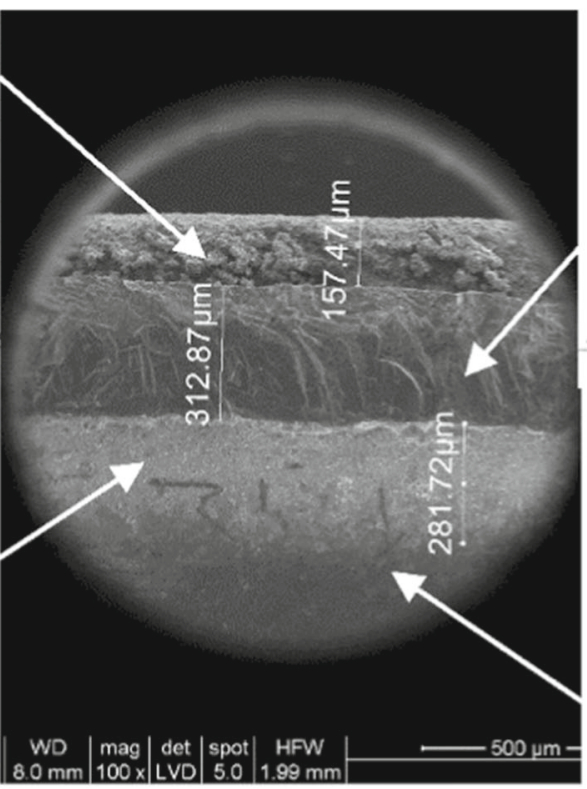

$\mathrm{Al}-10.91$ mass $\%$
$\mathrm{Ti}-59.28$ mass $\%$

C -6.22 mass $\%$

O - 9.00 mass $\%$

$\mathrm{Al}-20.55$ mass $\%$

$\mathrm{Ti}-64.03$ mass $\%$ rika

1
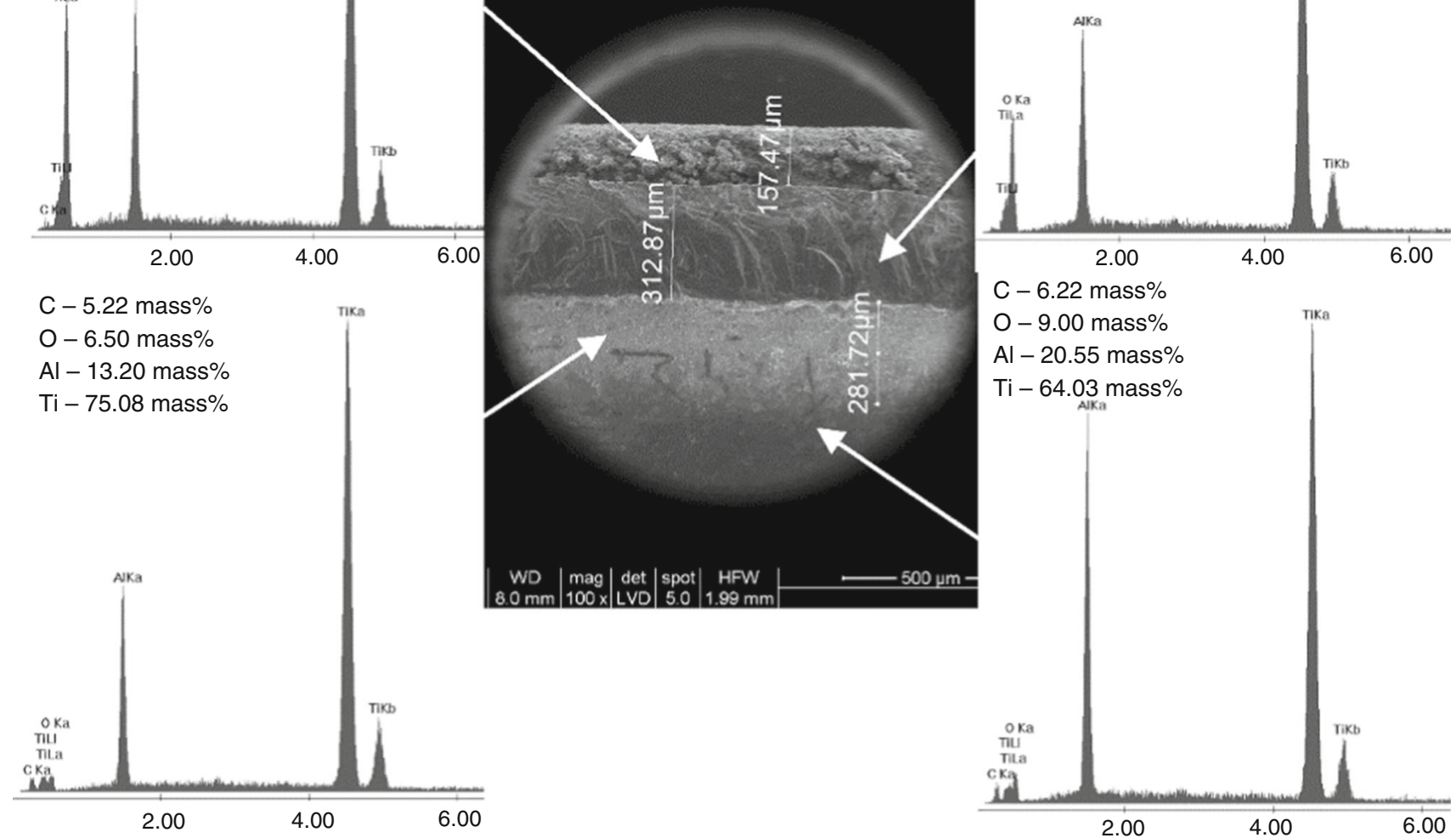

Fig. 18 Element distribution analysis (EDS) in welded area of $\mathrm{Ti}_{2} \mathrm{AlC}$ material

dark area of melted material reach in titanium, aluminum and carbon-element distribution analysis shown in Table 4. In this part of the cut, there are visible recrystallized particles composed almost $50 / 50 \%$ of titanium and aluminum which can correspond to $\mathrm{TiAl}$ phase. Also there are visible small amounts of carbon-signal collection error of EDS. Around the inner part of the cut, there are the recrystallized particles oriented in parallel direction to laser beam. These particles are reach in $\mathrm{Ti}, \mathrm{Al}$ and $\mathrm{C}$ which can correspond to MAX and TiC phases (Table 4, Fig. 16, point 2). In further perpendicular distance from the center of recrystallized area, the grains are oriented perpendicularly to acting laser beam (Fig. 16b). Figure 16c shows fine round grains in the tip of the cut, which can be related to material melting and dissolution process. EDS analysis shows no oxygen contamination in the material part treated by the laser beam.

The second process conducted on polycrystalline nanolaminate materials was welding by laser beam at continuous work mode due to good thermal shock resistance of MAX phases [21]. The welding process was made on selected samples of $\mathrm{Ti}_{2} \mathrm{AlC}$ and $\mathrm{Ti}_{3} \mathrm{AlC}_{2}$ materials. The 
optical microscopy observation of the weld surface made in the zone marked in Fig. 2 is illustrated in Fig. 17. The welding process was conducted with speed of $0.5 \mathrm{~mm} \mathrm{~s}^{-1}$ at $100 \mathrm{~W}$ power and $1-\mathrm{mm}$ laser beam spot allowed to join two parts of materials. The joining was not very strong but promising for future welding investigations. In Fig. 17, there is visible crack along the $\mathrm{Ti}_{2} \mathrm{AlC}$ weld, which is probably the result of high thermal stresses existing in this region. Thermal stresses are caused by low thermal conductivity coefficient of the porous $\mathrm{Ti}_{2} \mathrm{AlC}$ material and screw material fixing in the holder-after sample unscrewing the weld broke and the crack was generated. In case of $\mathrm{Ti}_{2} \mathrm{AlC}$ nanolaminate the width of the joining was around $1 \mathrm{~mm}$. Around 400 microns deposited layer around the weld area was observed as a result of material removal by flowing protective gas. The oxidization of the deposited material on the sample surface was confirmed by point element distribution analysis (EDS) shown in Fig. 18. The cut cross section indicates on the lack of cracks propagating to the material body (Fig. 18). In case of porous $\mathrm{Ti}_{2} \mathrm{AlC}$ ceramics the laser processing can be also important because of MAX phase application for loop pipe [34].

The thickness of the $\mathrm{Ti}_{3} \mathrm{AlC}$ welding layer is around $300 \mu \mathrm{m}$. In case of $\mathrm{Ti}_{3} \mathrm{AlC}_{2}$-sintered sample the joining
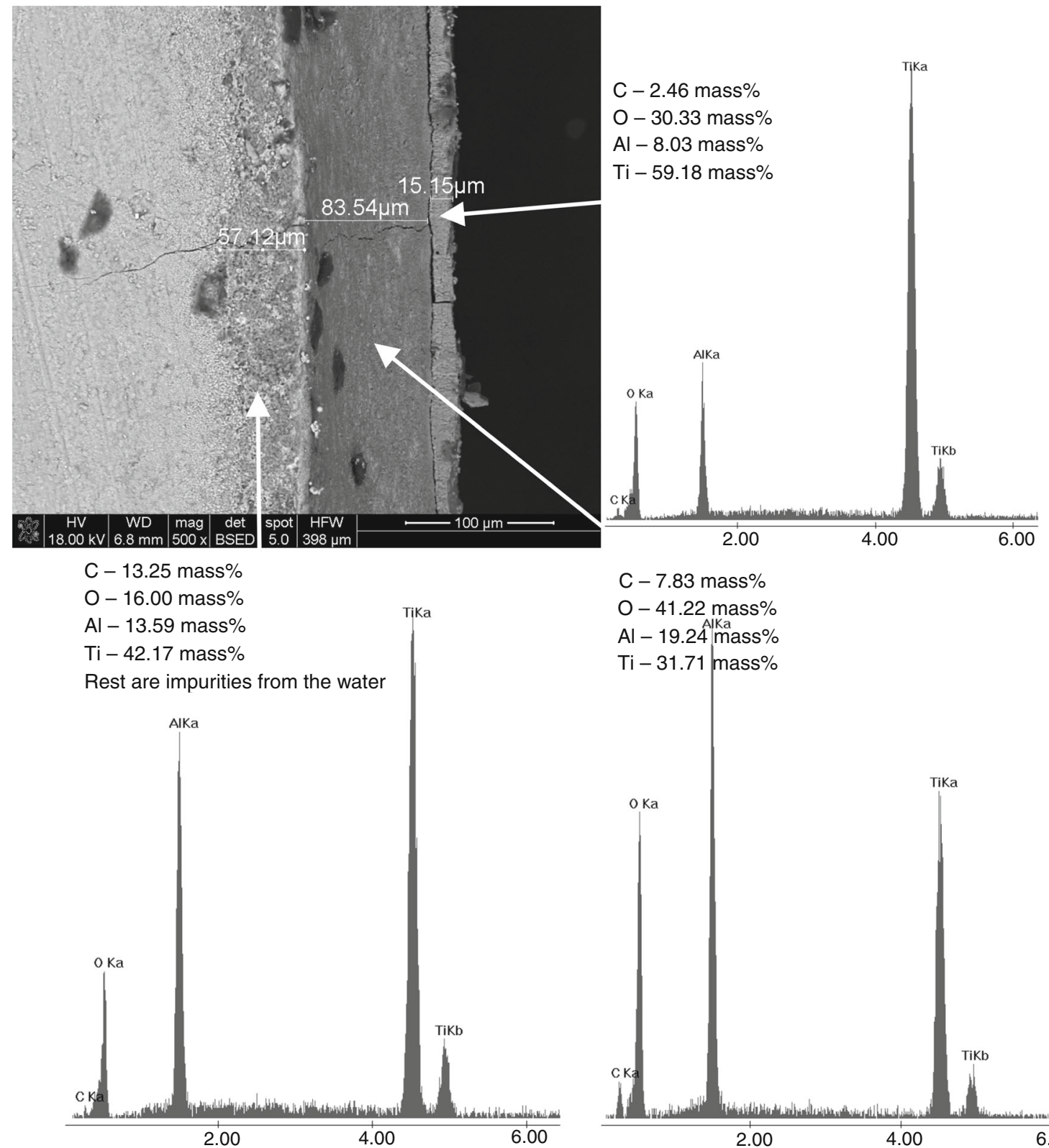
was stronger-Fig. 18. Only two cracks were visible across the weld, but no crack was in the joining line. In comparison with $\mathrm{Ti}_{2} \mathrm{AlC}$ probably some material removed from the border between the welded polycrystalline MAX beams was deposited in the middle of the joining area. The second layer of the $\mathrm{Ti}_{3} \mathrm{AlC}_{2}$ weld is similar to $\mathrm{Ti}_{2} \mathrm{AlC}$ and has a shape of typical weld. The $\mathrm{Ti}_{3} \mathrm{AlC}_{2}$ joining area is narrower, and it is about $0.7 \mathrm{~mm}$. The oxidize 0.3 width material deposited around weld area was also recorded-external 15-micron-thick layer in Fig. 19. The material joining thickness in case of $\mathrm{Ti}_{3} \mathrm{AlC}_{2}$ material is about 90 microns (Fig. 19). There are few cracks visible perpendicular to the material weld. That can be caused by fast cooling rate in the material body related to the high thermal conductivity. The material weld is oxidized, which is confirmed by EDS analysis.

\section{Conclusions}

- The hot-pressed $\mathrm{Ti}_{2} \mathrm{AlC}$ nanolaminates show two times deeper and wider cuts than in the case of $\mathrm{Ti}_{3} \mathrm{AlC}_{2}$ material, which resulted from higher porosity and lower thermal conductivity of $\mathrm{Ti}_{2} \mathrm{AlC}$ materials. In case of lower-temperature distribution rate in the material, the temperature in the laser cut area significantly increases which causes deeper cuts and fast material removal from this area.

- Laser processing analysis confirmed that it is possible to use this technology for MAX phase healing and local densification

- After $\mathrm{Ti}_{3} \mathrm{AlC}_{2} \mathrm{MAX}$ materials laser processing, the obtained cut was filled by recrystallized material containing $\mathrm{Ti}-\mathrm{Al}$ compounds. The cavity filling during laser cutting process is promising for material crack healing and possibility of nanolaminate material joining.

- The trials of MAX material joining confirm that it is possible to use laser beam in continuous work mode for welding process. The results show that there are still some cracks in the joining area, which could be solved in the future by further optimization of laser processing parameters, e.g., power density, process speed and length of laser pulse. The welding trials made in aggressive $\mathrm{CW}$ mode indicate on plausible need of use of nanosecond laser pulse mode.

Acknowledgements The research work was financed from the National Science Centre as a Project OPUS 6 No. UMO-2013/11/B/ ST5/02275 titled "Structure and basic physical properties of functional layered MAX phases." We want to thank very much Dr. Magdalena Ziąbka and MSc Barbara Trybalska for their help at scanning electron microscopy observations.
Open Access This article is distributed under the terms of the Creative Commons Attribution 4.0 International License (http://creative commons.org/licenses/by/4.0/), which permits unrestricted use, distribution, and reproduction in any medium, provided you give appropriate credit to the original author(s) and the source, provide a link to the Creative Commons license, and indicate if changes were made.

\section{References}

1. Wang XH, Zhou YC. Layered machinable and electrically conductive $\mathrm{Ti}_{2} \mathrm{AlC}$ and $\mathrm{Ti}_{3} \mathrm{AlC}_{2}$ Ceramics: a review. J Mater Sci Technol. 2010;26:385-416.

2. Barsoum MW, Salama I, Ei-Raghy T, Golczewski J, Porter WD, Wang $\mathrm{H}$, Aldinger HJ. Thermal and electrical properties of $\mathrm{Nb}_{2} \mathrm{AlC},(\mathrm{Ti}, \mathrm{Nb})_{2} \mathrm{AlC}$ and $\mathrm{Ti}_{2} \mathrm{AlC}$. Metall Mater Trans A. 2002;33A:2775-9.

3. Wang J, Wang J, Li A, Li J, Zhou Y. Theoretical study on the mechanism of anisotropic thermal properties of $\mathrm{Ti}_{2} \mathrm{AlC}$ and $\mathrm{Cr}_{2}$ AlC. J Am Ceram Soc. 2014;97:1202-8.

4. Wang P, Mei P, Hong X, Zhou W. Synthesis of $\mathrm{Ti}_{2} \mathrm{AlC}$ by hot pressing and its mechanical and electrical properties. Trans Nonferrous Met Soc China. 2007;17:1001-4.

5. Medkour Y, Roumili A, Maouche D, Louail L. 7: Electrical properties of MAX phases. In: Advances in science and technology of Mn + 1AXn Phases; 2012. p. 159-175.

6. Chen X, Bei G. Toughening mechanisms in nanolayered MAX phase ceramics - a review. Materials (Basel). 2017;10:366.

7. Wang $\mathrm{XH}$, Zhou YC. High-temperature behaviour of $\mathrm{Ti}_{2} \mathrm{AlC}$ in air. Oxid Met. 2003;59:303-20.

8. Wang J, Zhou Y. recent progress in theoretical prediction, preparation, and characterization of layered ternary transitionmetal carbides. Ann Rev Mater Res. 2009;39:415-43.

9. Radovic M, Barsoum MW. MAX phases: bridging the gap between metals and ceramics. Am Ceram Soc Bull. 2013;92:20-7.

10. Barsoum MW. MAX phases: properties of machinable ternary carbides and nitride. Weinheim: Wiley; 2013.

11. Ge Z, Chen K, Guo J, Zhou H, Ferreira JMF. Combustion synthesis of ternary $\mathrm{Ti}_{3} \mathrm{AlC}_{2}$ in $\mathrm{Ti}-\mathrm{Al}-\mathrm{C}$ system. J Eur Ceram Soc. 2003;23:567-74.

12. Shahin N, Kazemi Sh, Heidarpour A. Mechanochemical synthesis of $\mathrm{Ti}_{3} \mathrm{AlC}_{2}$ MAX phase from elemental powders of Ti. Al C Adv Powder Technol. 2016;27:1775-80.

13. Koniuszewska A, Naplocha K. Microwave assisted self-propagating high-temperature synthesis of $\mathrm{Ti}_{2} \mathrm{AlC}$ max phase. Compos Theory Pract. 2016;16:109-11.

14. Han J-H, Hwang S-S, Lee D, Park S-W. Synthesis and mechanical properties of $\mathrm{Ti}_{3} \mathrm{AlC}_{2}$ by hot pressing $\mathrm{TiC}_{\mathrm{x}} / \mathrm{Al}$ powder mixture. J Eur Ceram Soc. 2008;28:979-88.

15. Wang $\mathrm{P}$, Mei B, Hong X, Zhou W. Synthesis of $\mathrm{Ti}_{2} \mathrm{AlC}$ by hot pressing and its mechanical and electrical properties. Trans Nonferrous Met Soc China. 2007;17:1001-4.

16. Yang C, Jin S, Liang B, Liu G, Duan L, Jia S. Synthesis of $\mathrm{Ti}_{3} \mathrm{AlC}_{2}$ by spark plasma sintering of mechanically milled 3Ti/ xA1/2C powder mixtures. J Alloy Compd. 2009;472:79-83.

17. Zhou A. Methods of MAX-phase synthesis and densification: II. In: Advances in science and technology of Mn + 1AXn phases; 2012.

18. Wang $\mathrm{X}$, Zhou Y. Solid-liquid reaction synthesis of layered machinable $\mathrm{Ti}_{3} \mathrm{AlC}_{2}$ ceramic. J Mater Chem. 2002;12:455-60.

19. Hu C, Sakka Y, Tanaka H, Nishimura T, Grasso S. Fabrication of textured $\mathrm{Nb}_{4} \mathrm{AlC}_{3}$ ceramic by slip casting in a strong magnetic field and spark plasma sintering. J Am Ceram Soc. 2011;94:410-5. 
20. Nowotny H, Schuster JC, Rogl P. Structural chemistry of complex carbides and related compounds. J Solid State Chem. 1982;44:126-33.

21. Bao YW, Wang XH, Zhang HB, Zhou YC. Thermal shock behaviour of $\mathrm{Ti}_{3} \mathrm{AlC}_{2}$ from between $200{ }^{\circ} \mathrm{C}$ and $1300{ }^{\circ} \mathrm{C}$. J Eur Ceram Soc. 2005;25:3367-74.

22. Song GM. 11: Self-healing of MAX phase ceramics for high temperature applications: evidence from $\mathrm{Ti}_{3} \mathrm{AlC}_{2}$. In: Advances in science and technology of Mn + 1AXn phases; 2012, p. 271-288.

23. Chlubny L, Lis J, Chabior K, Chachlowska P, Kapusta C. Processing and properties of MAX phases-based materials using SHS technique. Arch Metall Mater. 2015;60:859-63.

24. Radovic M, Barsoum MW, Ganguly A, Zhen T, Finkel P, Kalidindi $\mathrm{SR}$, Lara-Curzio $\mathrm{E}$. On the elastic properties and mechanical damping of $\mathrm{Ti}_{3} \mathrm{SiC}_{2}, \mathrm{Ti}_{3} \mathrm{GeC}_{2}, \mathrm{Ti}_{3} \mathrm{Si}_{0.5} \mathrm{Al}_{0.5} \mathrm{C}_{2}$ and $\mathrm{Ti}_{2} \mathrm{AlC}$ in the $300-1573 \mathrm{~K}$ temperature range. Acta Mater. 2006;54:2757-67.

25. Ching $\mathrm{W}-\mathrm{Y}$, Mo $\mathrm{Y}$, Aryal S, Rulis $\mathrm{P}$. Intrinsic mechanical properties of 20 MAX-Phase compounds. J Am Ceram Soc. 2013;96:2292-7.

26. Kozak K, Dosi A, Bućko MM, Chlubny L, Lis J, Antou G, Chotard $\mathrm{T}$. Investigation of the mechanical behavior of MAX phases by acoustic emission technique. Mat Sci Eng A. 2017;707:73-80.

27. Kozak K, Dosi A, Antou G, Pradeilles N, Chotard T. Characterization of thermomechanical behavior of $\mathrm{Ti}_{3} \mathrm{SiC}_{2}$ and $\mathrm{Ti}_{2} \mathrm{AlC}$ ceramics elaborated by spark plasma sintering using ultrasonic means. Adv Eng Mater. 2016;18:1952-7.

28. Pang WK, Low IM, O'Connor BH, Sun ZM, Prince KE. Oxidation characteristics of Ti3AlC2 over the temperature range 500-900 ${ }^{\circ} \mathrm{C}$. Mater Chem Phys. 2009;117:384-9.

29. Song GM, Pei YT, Sloof WG, Li SB, Hosson JTM, van de Zwaag S. Early stages of oxidation of $\mathrm{Ti}_{3} \mathrm{AlC}_{2}$ ceramics. Mater Chem Phys. 2008;112:762-8.

30. Xu X, Li Y, Zhu J, Mei B. High-temperature oxidation behavior of $\mathrm{Ti}_{3} \mathrm{AlC}_{2}$ in air. Trans Nonferrous Met Soc China. 2016;16:869-73.

31. Qian XK, He XD, Li YB, Sun Y, Li H, Xu DL. Cyclic oxidation of $\mathrm{Ti}_{3} \mathrm{AlC}_{2}$ at $1000-1300^{\circ} \mathrm{C}$ in air. Corros Sci. 2011;53:290-5.

32. Ai T. High-temperature oxidation of behaviour of un-dense Ti3AlC2 material at $1000{ }^{\circ} \mathrm{C}$ in air. Ceram Int. 2012;38:2537-41.

33. Khadzhai GY, Vovk RV, Prichna TA, Gevorkyan ES, Kislitsa $\mathrm{MV}$, Solovjov AL. Electrical and thermal conductivity of the $\mathrm{Ti}_{3} \mathrm{AlC}_{2}$ MAX phase at low temperatures. Low Temp Phys. 2018;44:451-2.

34. Xu J, Zou Y, Yang D, Fan M. Development of biporous $\mathrm{Ti}_{3} \mathrm{AlC}_{2}$ ceramic wicks for loop pipe. Mater Lett. 2013;91:121-4.

Publisher's Note Springer Nature remains neutral with regard to jurisdictional claims in published maps and institutional affiliations. 